\title{
EL TERRORISMO DE ESTADO. EL PROBLEMA DE SU LEGITIMACIÓN E ILEGITIMIDAD
}

ERNEsTo Garzón VaLdés

Instituto de Cienctas Poltticas

UNIVERSIDAD DE MAINZ-JOHANNES GUTENBERG

Deseo analizar aquí el terrorismo de Estado desde el punto de vista de su legitimación fáctica y de su ilegitimidad ética. Me interesa primordialmente considerar los argumentos que quienes propician o practican el terrorismo de Estado suelen utilizar para justificarlo. Aunque estos argumentos serán ilustrados principalmente con declaraciones de teóricos y protagonistas del terrorismo estatal practicado en la Argentina durante los años del llamado "Proceso de reorganización nacional" (1976-1983), en el presente estudio no pretendo aportar nuevos datos históricos sobre el caso argentino. Tampoco deseo formular consideraciones que serian válidas sólo para él, sino más bien exponer algunas reflexiones sobre el terrorismo de Estado como fenómeno político en general, otorgando especial importancia, por una parte, al análisis conceptual y, por otra, a la perspectiva de la ética normativa.

En lo que sigue habré de precisar la distinción conceptual entre legitimación y legitimidad (1), proponer una definición del terrorismo de Estado (2), recordar los argumentos esgrimidos para su justificación (3) y poner de manifiesto su inaceptabilidad ética (4).

\section{Distinción conceptual entre legitimación y legitimidad}

El concepto "legitimación" designa la aceptación de la regla básica de un sistema político (a la que, siguiendo la terminología propuesta por H.L.A. Hart [1961], llamaré "regla de reconocimiento") por parte de quienes directa o indirectamente detentan el poder institucionalizado. En la clásica formulación de Max Weber, esta aceptación resulta de la existencia de una "creencia en la legitimidad", es decir, de la creencia de que las reglas del sistema son las más adecuadas para la respectiva sociedad. No hay duda que Max Weber utilizaba la expresión "creencia en la legitimidad" en un sentido valorativamente neutro. Sin embargo, como este vocablo puede fácilmente sugerir una asociación semántica con el concepto valorativamente positivo de "legitimidad", prefiero 
recurrir aquí a la frase "punto de vista interno" (propuesta también por Hart) para designar la perspectiva desde la cual la regla de reconocimiento de un sistema político es aceptada como pauta suprema de comportamiento en la respectiva sociedad.

La consideración del punto de vista interno como elemento fundamental para la existencia de un sistema político y su estabilidad tiene, conviene recordarlo, una larga tradición en la teoría del Estado; ella se remonta, por lo menos, a Marsilio de Padua y fue reactualizada a comienzos de los años 30 por Hermann Heller cuando decía:

una situación fáctica de poder [...] se convierte en una situación de poder relativamente duradera y, con ello, en una organización en algún sentido amplio o estricto, sólo si las "decisiones" de quienes detentan el poder son obedecidas por lo menos por una parte de los sometidos a este poder -y por cierto por aquella parte que es fundamental para la estructura del poder - a más de por otros motivos (hábito, promoción de los propios intereses), porque se les presentan como normas debidas, modélicas o vinculantes. (1971, t. 3, p. 17)

La legitimación es condición necesaria pero no suficiente para la existencia de todo sistema político.

El concepto "legitimidad" designa la concordancia de los principios sustentados por la regla de reconocimiento del sistema con los de la moral crítica o ética. La legitimidad no es condición necesaria ni suficiente para la existencia de un sistema político (cfr. Garzón Valdés, 1987, pp. 5 ss.).

Por definición, quienes adoptan el punto de vista interno predican la legitimidad del sistema ya que "los grupos considerarán a un sistema político como legítimo o ilegítimo en la medida en que sus valores coincidan o no con las propias valoraciones primarias” (Seymour Martin Lipset, 1959, pp. 86 s.). Sostener que alguien adopta el punto de vista interno pero considera que las reglas a las que se adhiere no son las correctas sería caer en una manifiesta contradicción. En el caso del terrorismo de Estado, quienes adoptan el punto de vista interno consideran, por supuesto, que el sistema posee legitimidad y que sus principios y normas son dignos de respeto.

Dado que ello es así, podría pensarse que la distinción entre legitimación y legitimidad es superflua. Sin embargo, conviene distinguir claramente el concepto de legitimación del de legitimidad. En caso contrario, se cometen dos graves errores conceptuales. El primero consiste en el llamado positivismo ideológico, es decir, sostener que cada sistema posee su propia fuente de legitimidad. Todo sistema, por el hecho de adoptar un procedimiento para la formulación y modificación de sus reglas, poseería legitimidad: se autoabastecería de justificaciones éticas. Utilizando una frase de François Bourricaud (1961, p. 7), podría decirse entonces que legítimo es "un poder que acepta o hasta instituye su propio proceso de legitimación". Por definición, 
todo sistema político poseería legitimidad: tanto el nacionalsocialista como el del apartheid o el del terrorismo de Estado practicado en América Latina. El error del positivismo ideológico consiste en creer que la aceptación o el cumplimiento de las normas básicas del sistema por parte de sus creadores o destinatarios proporcionan razones suficientes para la justificación moral de los actos que ellos realizan.

El segundo error es el de la falacia naturalista, es decir, sostener que porque en una determinada sociedad los grupos dirigentes aceptan ciertas reglas de comportamiento, ellas son moralmente debidas. Se produce aquí un paso del ámbito del ser al del deber ser, con las fatales consecuencias lógicas que conocemos, por lo menos, desde Hume.

Por supuesto que admitir la distinción entre legitimación y legitimidad presupone admitir también la existencia de valores objetivos y universales, más allá de su reconocimiento circunstancial en determinadas sociedades. Quien sustente un radical relativismo ético no estará dispuesto a aceptar la distinción aquí propuesta y sostendrá, siguiendo, por ejemplo, a Niklas Luhmann, que el problema de la legitimidad se agota en el "convencimiento fácticamente generalizado de la validez del derecho, de la obligatoriedad de determinadas normas o decisiones o del valor de los principios que las justifican” (1969, p. 27). No he de entrar al análisis de la problemática del relativismo ético y de la posibilidad de su superación ( $c f r$. al respecto, entre otros, James $S$. Fishkin 1984, e Ingemar Hedenius, 1981). Aquí tan sólo me interesa subrayar que la legitimidad no es un problema técnico que se solucione a través de un instrumental eficaz para lograr que la gente crea en la aceptabilidad de la respectiva regla de reconocimiento, sino que es un problema esencialmente ético. No comprender la diferencia que existe entre lo bueno técnico o instrumental y lo bueno ético es lanzarse por una vía que directamente conduce al positivismo ideológico.

He señalado más arriba que la legitimación, o punto de vista interno, es una condición necesaria aunque no suficiente para la existencia de un sistema político. Se requiere, además, que quienes sustentan el punto de vista interno tengan el poder suficiente como para imponer su regla de reconocimiento. Punto de vista interno y poder de imposición son dos condiciones necesarias cuya conjunción las transforma también en suficientes.

El régimen del terrorismo de Estado existió y sigue existiendo justamente porque satisface estas dos condiciones.

\section{El concepto del terrorismo de Estado}

Por terrorismo de Estado habré de entender aquí aquel ejercicio del poder estatal que está caracterizado, por lo menos, por las siguientes notas: 
a) Afirmación de la existencia de una "guerra vertical" con un enemigo infiltrado en todos los niveles de la sociedad, que suele actuar como agente de una confabulación internacional cuya finalidad es la eliminación de valores aceptados como absolutos por quienes detentan el poder:

La guerra vertical se libra dentro de cada pueblo, en la entraña de cada nación, con propósitos políticos, y cuyo objetivo final es el del convertir a un determinado país en satélite de otro o de cambiar la esfera de influencia internacional en la que se encuentre. (Alegato de Roberto Eduardo Viola ante la Cámara Nacional de Apelaciones en lo Criminal y Correccional Federal, el 12 de octubre de 1985; cfr. El Diario del Juicio, no. 22, 22 de octubre de 1985)

La creencia en la necesidad de responder con el terror a la "guerra vertical", alentada también por agentes internacionales, fue, como es sabido, invocada por León Trotsky (1961, p. 64) para justificar el terror rojo:

Sin el terror rojo, la burguesía rusa, conjuntamente con la burguesía mundial, nos hubiera estrangulado mucho antes del advenimiento de la revolución en Europa.

Robespierre no pensaba de manera muy diferente cuando afirmaba:

Todos los corazones no han cambiado pero, icuántos rostros están enmascarados! iCuántos traidores se mezclan en nuestros asuntos para arruinarlos! (1965, p. 231)

o bien;

Hay que sofocar a los enemigos interiores y exteriores de la República o perecer con ellos; por lo tanto, en esta situación, la primera máxima de vuestra política debe ser conducir al pueblo por la razón y a los enemigos del pueblo, por el terror. (1965, p. 221)

El hecho de que aquí los "enemigos infiltrados" fueran aristócratas y no izquierdistas o burgueses, como en los casos de Viola o de Trotsky respectivamente, no constituye una diferencia relevante que permita poner en duda la importancia de la creencia en la "guerra vertical" y el temor que ello provoca en quienes detentan el poder.

b) Delimitación imprecisa de los hechos punibles y eliminación del proceso judicial para la determinación de la comisión de un delito:

Se ha comprobado $[\ldots]$ que las personas aprehendidas no eran puestas a disposición de la Justicia civil ni militar, salvo en contados casos, que no debía darse información sobre las detenciones, ni siquiera a los jueces [...] (Sentencia de la 
Cámara Nacional de Apelaciones en lo Criminal y Correccional Federal del 9. 12. 1985 en el juicio a los ex comandantes de las Juntas Militares)

Un cjemplo de una delimitación imprecisa de hechos punibles es la establecida en el $\S 5$ de la Ordenanza del derecho penal especial de guerra (KSStVO) del 17 de agosto de 1938 en la Alemania nazi, que regulaba el tipo penal del "derrotismo". Como observa con razón Ulrich Klug (1987, p. 98; 1989, p. 156), esta disposición era, "debido a su formulación sumamente amplia y vaga, un instrumento de destrucción especialmente adecuado".

El 6 de abril de 1945 en el KZ Sachsenhausen/Oranienburg se llevó a cabo un "procedimiento" a través del llamado "Consejo de Guerra de la SS" en el que fueron condenados a muerte el almirante Wilhelm Canaris, el mayor general Hans Oster, el pastor Dietrich Bonhoeffer, el juez de Estado Mayor Dr. Karl Sack, el capitán Ludwig Gehre y el consejero de justicia del Reich Hans von Dohnanyi. También en este caso, como en muchos otros del terrorismo de Estado nacionalsocialista, se violaron las disposiciones sobre el proceso judicial vigente. Al respecto observa Ulrich Klug (1987, p. 109; 1989, p. 167 s.):

El carácter de antijuridicidad del procedimiento es aún mayor debido al hecho de que los "Consejos de Guerra" tuvieron como jueces auxiliares a comandantes de campos de concentración sujetos a directivas y en modo alguno imparciales, y tampoco se designaron defensores, a pesar de que ello era necesario en virtud de las disposiciones entonces vigentes pues estaban en juego penas de muerte. También era contrario a derecho la no designación de un funcionario que labrara las actas y registrara el cumplimiento de las formalidades esenciales.

El artículo 22 de los Principios de la Jurisdicción Penal de la Unión Soviética de 1937 eliminaba el proceso judicial al establecer:

Una sentencia del Fiscal de Estado puede imponer pena de exilio a personas reconocidas como socialmente peligrosas, aun cuando no se haya iniciado ningún procedimiento penal en contra de estas personas por haber cometido un crimen o delito específico y también en aquellos casos en lós que estas personas hayan sido absueltas judicialmente de la acusación de haber cometido un crimen específico. (Cfr. A. James Gregor, 1989, p. 161)

c) Imposición clandestina de medidas de sanción estatal prohibidas por el orden jurídico oficialmente proclamado (torturas y homicidio, entre otras):

Se ha demostrado que, pese a contar los comandantes de las fuerzas armadas que tomaron el poder el 24 de marzo de 1976, con todos los instrumentos legales para llevar a cabo la represión de modo lícito, sin desmedro de su eficacia, optaron por la puesta en marcha de procedimientos clandestinos e ilegales sobre la base de órdenes que impartieron los enjuiciados. (Sentencia de la Cámara Nacional de 
Apelaciones en lo Criminal y Correccional Federal del 9. 12. 1985 en el juicio a los ex comandantes de las Juntas Militares)

El carácter clandestino de las medidas de coacción estatal fue propio también del terrorismo estalinista de 1935-1939. Alexander Dallin y George Breslauer $(1970$, p. 28$)$ lo describen así:

liquidación sin anuncio público $[\ldots]$ asesinato clandestino; deportación y exilio por varios años, incluyendo la internación masiva en campos de trabajos forzados.

Tienen, sin duda, razón Raymond D. Duvall y Michael Stohl cuando afirman: "La publicidad no pertenece a la esencia del terrorismo [...] el terrorismo de Estado es, por lo general, una acción sumamente secreta" (1983, p. 188). En este sentido, es interesante recordar, que las acciones del terrorismo de Estado suelen ser oficialmente imputadas o bien a grupos que escapan al control del gobierno, a grupos paraestatales, no institucionalizados públicamente (como es el caso de los Escuadrones de la Muerte o de la Alianza Anticomunista Argentina) o a servicios "secretos" que, por definición, escapan a toda publicidad (basta recordar los $B$-specials creados por los británicos en Irlanda en 1921 o la Secret Army Organization organizada por el FBI en San Diego en 1971 para acciones terroristas en contra de los pacifistas [cfr. David Wise, 1978, p. 319] y, por supuesto, la Gestapo).

En el caso de la Alemania nazi, Hans Buchheim $(1985$, p. 151) se ha referido al interés de la Policía Política, vinculada a la SS, en no estar sujeta a limitaciones legales públicas como las impuestas por la Ordenanza dictada con motivo del incendio del Reichstag. Así, en una circular del Departamento Central de Seguridad del Reich del 15 de abril de 1940 se dice:

La validez jurídica de las disposiciones de la policía del Estado no depende del hecho de que la Ordenanza del Presidente del Reich para la protección del pueblo y del Estado del 28 de febrero de 1933 sea utilizada como fundamento jurídico para estas disposiciones ya que la competencia de la Policía Políica [... ] no deriva de leyes y ordenanzas particulares sino de la misión general (que le es encomendada).

La divergencia entre el ordenamiento jurídico proclamado y la regla de reconocimiento aceptada (no hay que olvidar que, por ejemplo, los miembros de las juntas militares argentinas juraban respetar la Constitución nacional) es explicada por los actores del terrorismo de Estado haciendo referencia a la situación de "guerra vertical". La contradicción entre las sanciones impuestas por el terrorismo estatal y el orden jurídico proclamado ha sido observada también por Alfred Grosser (1989, p. 30) en el caso del terror de 1793-94:

Sigue, con todo, abierta la cuestión acerca de la culpa de tantos pseudoprocesos y ajusticiamientos, de un tal abuso de los principios que se acababan de procla- 
mar. Se puede investigar cómo grupos de revolucionarios libertarios se dejaron convencer paso a paso o se convencieron ellos mismos de que podían permitir muertes ilegales o promover leyes contrarias a esos principios.

Es interesante recordar con respecto a la Alemania nazi los fallos de la llamada "Corte de Justicia del Pueblo" y la sentencia de la Corte de Justicia Federal del 28 de junio de 1956 en el caso Metzger. En los fundamentos del fallo, se señala que "el abuso del $\S 91$ b del Código Penal por parte de la Corte de Justicia del pueblo no tiene nada que ver con la administración de justicia”. Se trataría "tan sólo de la utilización de formas judiciales para una muerte ilegal [...] una tal administración de 'justicia' revela su verdadera esencia como instrumento del terror" (cfr. Ulrich Klug, 1987, p. 97; 1989, p. 154).

Es justamente la discrepancia entre el orden jurídico proclamado y la realidad lo que permite calificar de farsa a los procesos estalinistas y a los de la Corte de Justicia del Pueblo.

Christopher Mitchell et al. (1986, p. 13) han expresado sus dudas acerca de la conveniencia de introducir la nota de ilegalidad en la definición de terrorismo de Estado y aducido que la legislación antiterrorista en la República de Sudáfrica o la "justicia islámica” en Irán o Sudán son intentos de legalizar la difusión del terrorismo de Estado. En este sentido, “acciones que esencialmente implican afectar el comportamiento de la gente induciendo un alto grado de temor pueden fácilmente estar respaldadas por la ley y, en este sentido, ser completamente no arbitrarias" (ibid.).

El ejemplo de Sudáfrica no parece ser muy afortunado para apoyar la tesis de Mitchell et al., si se toman en cuenta las declaraciones de Dirk Coetzee, uno de los protagonistas de la represión sudafricana, publicadas el 10 de mayo de 1990 en el semanario Stern (no. 20, pp. 36-40). Puede allí leerse el siguiente diálogo:

- Stern: ¿Estaba Ud. orgulloso de pertenecer a la Policía de Seguridad?

- Coetzee: Sí; éramos un grupo de elegidos. Estábamos por encima de la ley.

-Stern: La Policía de Seguridad parecía estar tan al margen de la ley que sus miembros podían también cometer delitos en provecho propio.

- Coetzee: Correcto. Algunos ganaban dinero con el contrabando de divisas. Otros robaban autos, por ejemplo, de miembros del ANC [African National Congress] y se metían en el propio bolsillo el dinero obtenido de su venta [...] Todos estábamos implicados en acciones ilegales.

Como es bien sabido, los miembros de la represión terrorista argentina también recurrían al saqueo de los bienes de sus víctimas como parte de la retribución de sus tareas, violando por cierto las disposiciones penales vigentes (cfr. El Diario del Juicio, no. 22, 22 de octubre de 1985). 
Pero lo fundamental no es, desde luego, la mera existencia de contraejemplos ilustrativos sino el aspecto conceptual. La nota de ilegalidad es relevante ya que es justamente ella la que permite lograr un "alto grado de temor" en la población al mantener abierta la clase de los destinatarios de las medidas de terrorismo de Estado. El miedo que engendra el terrorismo de Estado no es el temor que puede sentir quien se sabe perseguido por su pertenencia a un determinado grupo racial o religioso sino la sensación de estar librado a la arbitrariedad imprevisible de quienes detentan el poder. Toda disposición legal (a menos que se trate de una disposición como la del artículo 22 de los Principios de Jurisdicción Penal de la Union Soviética citado y que es considerado como "único en la jurisprudencia internacional"; cfr. A. James Gregor, 1989, p. 161) reduce el margen de inseguridad, y es esta última la fuente principal del temor ciudadano al que Christopher Mitchell et al. consideran como rasgo esencial del terrorismo de Estado. Que las medidas legales pueden ser aborreciblemente injustas es obvio, pero ello no autoriza a ignorar la distinción entre seguridad injusta y arbitrariedad terrorista.

Además, el carácter clandestino de las actividades del terrorismo de Estado es relevante, pues es un dato más que permite distinguir el régimen de los Estados totalitarios sin más del de gobiernos que practican el terrorismo de Estado, sean éstos totalitarios o no.

Dada la tendencia de los regímenes totalitarios a aplicar medidas de terrorismo de Estado, es comprensible que exista también la tendencia a creer que sólo ellos la practican. La creencia es comprensible, pero errónea.

Michael Stohl $(1983$, p. 6) ha subrayado acertadamente la falsedad de la tesis simplificadora según la cual sólo los Estados no democráticos, totalitarios, fascistas o comunistas practicarían el terrorismo de Estado, e ilustrado con elocuentes ejemplos acciones de terrorismo de Estado en democracias liberales occidentales (con respecto al carácter terrorista de la campaña en contra de los Black Panthers en 1969-1970 en los Estados Unidos y las actividades francesas en Argelia a fines de los 50, cfr. entre otros, Ted Robert Gurr, 1986, p. 49 s.).

La tesis simplificadora se basa en la falacia que consiste en inferir del hecho de que los gobiernos totalitarios suelen practicar el terrorismo de Estado la conclusión de que ello es una característica que les pertenece en exclusividad. Esta falacia, a la que los lógicos llaman "conversión falsa" consiste en creer que porque una clase de objetos $X$ tiene la propiedad $P, P$ es exclusiva de $X$, lo que puede ser obviamente falso. Del hecho de que los caballos sean cuadrúpedos no se infiere que sean los únicos animales cuadrúpedos que existan, y significaría, desde luego, empobrecer la investigación sobre los cuadrúpedos reducirla al caso de los caballos. Justamente porque el razonamiento es falaz, puede inducir a error enfocar el terrorismo de Estado desde la perspectiva de los estudios realizados sobre el totalitarismo. Por el contrario, el rechazo de la 
tesis simplificadora permite admitir los casos de terrorismo de Estado practicados en el Primer Mundo y calificar de correcta la observación de Raymond D. Duvall y Michael Stohl (1983, p. 196):

Los gobiernos en sociedades del Primer Mundo a veces se consideran incapaces de enfrentarse eficazmente con las amenazas a la ley y al orden, dentro de los límites del proceso debido [...] En tales situaciones, prseden recurrir a estrategias de terrorismo. Esto es particularmente así en la medida en que tal estrategia es percibida como la única que presenta un bajo riesgo político en la situación particular. El bajo riesgo puede ser una función de la habilidad del gobierno para minimizar la publicidad de su estrategia terrorista.

d) Aplicación difusa de medidas violentas de privación de la libertad, la propiedad o la vida, con prescindencia, en muchos casos, de la identidad del o de los destinatarios de las mismas y de los actos u omisiones de los que puedan ser responsables; la aplicación de la violencia a víctimas inocentes contribuye precisamente a reforzar la "eficacia" del terror:

Se han establecido los hechos que, como derivación de dichas órdenes, se cometieron en perjuicio de gran cantidad de personas, tanto pertenecientes a organizaciones subversivas como ajenas por completo a ellas; y que tales hechos consistieron en el apresamiento violento, el mantenimiento en detención en forma clandestina, el interrogatorio bajo tormentos y, en muchos casos, la eliminación física de las víctimas, lo que fue acompañado en gran parte de los hechos por el saqueo de los bienes de sus viviendas. (El Diario del Juicio, loc. cit.)

Las notas b) y d) confieren una notoria "eficacia” al terrorismo de Estado en el sentido de que cada cual puede considerarse una víctima potencial. Sin embargo, Raymond D. Duvall y Michael Stohl $(1983$, p. 185) han sostenido que las nociones de inocencia y de violencia indiscriminada son irrelevantes para la definición del terrorismo de Estado:

[Hay] poca evidencia de que la inocencia sea una categoría interpretativa importante a través de la cual los testigos mismos ven la violencia terrorista. En la medida en que los testigos no tienen un conocimiento claro del status de las víctimas en términos de culpabilidad o inocencia, esta última no es apta como medio conceptual a través del cual los testigos puedan considerarse a ellos mismos como víctimas probables y, por lo tanto, sentirse aterrorizados [...] parece dudoso que la atribución de ese status [inocencia] a la víctima por parte de un testigo pueda ser suficiente para engendrar en él la creencia de ser una probable víctima.

Pero, si se elimina la característica de la inocencia de muchas de las víctimas del terrorismo de Estado y, razonando al contrario, se piensa que sólo las per- 
sonas “culpables" de acuerdo con la legislación vigente son objeto de las medidas ferozmente coactivas del gobierno, se borra la distinción entre régimen totalitario y régimen que practica el terrorismo de Estado. Además, si el testigo sabe que el destinatario de la medida terrorista no es inocente y sabe también que él lo es, no se comprende cómo puede no sentirse víctima potencial. En ese caso su inocencia sería la mejor garantía de que nunca será destinatario de una medida terrorista. Héctor A. Murena, fino ensayista argentino cuya obra merecería ser estudiada por quienes se interesan por la cultura política latinoamericana en general y argentina en particular, describió acertadamente ya años antes de la implantación del terrorismo de Estado en la Argentina la estrategia de la persecucion de inocentes:

La justicia no tenía por objeto castigar a los culpables, sino hacer sentir al resto de los ciudadanos que ellos por el momento pertenecían al núcleo de los buenos, de los no culpables, de los elegidos, pero que en el mañana podían repentinamente cambiar de estado. (H.A. Murena, 1970, p. 106 ss.)

La inocencia no es, pues, garantía alguna contra el terror. Por el contrario: "Las represalias en contra de personas manifiestamente inocentes pueden ser utilizadas - y, a menudo, lo son- para disuadir a la gente de la comisión de actos hostiles [...]" (Michael Nicholson, 1986, p. 33)

Es obvio que la calificación de culpable sólo puede ser aplicada a quienes sean responsables causalmente de una acción u omisión. El hecho de que en la Alemania nazi se castigara a personas por su pertenencia a una determinada raza (como en el caso de los judíos y gitanos) y no por sus acciones u omisiones, es un testimonio más de su barbarie y puede inducir a pensar que el terrorismo de Estado es patrimonio exclusivo de este tipo de sistemas. Sin embargo, la diferencia consiste en que en el caso del nazismo la clase de estos "culpables" (desde luego inocentes, por no ser autores de ninguna acción u omisión) estaba delimitada expresamente mientras que, en el caso del terrorismo de Estado (como se sostendrá explícitamente en e)), la clase de los "culpables" es abierta. Esta delimitación de la clase de los "culpables" es lo que le permite afirmar a Hans Buchheim (1985, p. 173):

[L]as leyes de Nuremberg pusieron fin, en el ámbito de la discriminación de los judíos, a la inseguridad jurídica predominante hasta entonces y que favorecía todo tipo de terror; ellas crearon una norma que prometía una cierta posibilidad de protección a las víctimas. Naturalmente el contenido material de las lyes raciales era inicuo pero, a diferencia de la situación hasta entonces imperante, era una iniquidad calculable y la experiencia enseña que aquélla es más fácil de soportar que la pura arbitrariedad incalculable [...] los asesinos [del holocausto] no pueden invocar las leyes de Nuremberg como justificación por lo menos parcialmente legal de sus actos ya que estas leyes no fueron un eslabón en la cadena del terror extranormativo sino más bien la interrumpieron transitoriamente. 
En la medida en que los jerarcas nazis (y ello sucedió, desde luego, con harta frecuencia) aplicaban sus medidas coactivas a quienes no estaban incluidos en la clase legal de los "culpables", practicaban justamente terrorismo de Estado, al que con razón Buchheim llama "terror extranormativo".

Este comportamiento extranormativo contribuye decididamente al logro de un objetivo esencial del terrorismo de Estado, es decir:

e) Infundir en la población el temor fundado de que, en principio, nadie está a salvo de la coacción arbitraria por parte de los órganos gubernamentales. Esta afirmación puede parecer, a primera vista, demasiado fuerte. En efecto, si nadie puede estar seguro de que no será víctima del terrorismo de Estado, sus medidas carecerían de todo sentido ya que los ciudadanos no sabrían cómo actuar para evitarlas. Se perdería así el efecto de demostración, que suele ser considerado esencial para este tipo de regímenes (cfr., por ejemplo, Grant Wardlaw 1982, p. 16). La eficacia del terrorismo de Estado se mediría justamente por la destrucción del "enemigo" y la adopción de una actitud de obediencia por parte del resto de la población. Aceptar la ilimitación de la clase de los posibles destinatarios de las medidas del terrorismo de Estado implicaría vaciarlo de todo contenido instrumental. Según esta tesis, la clase de los destinatarios está definida y, dentro de ella, se eligen, de acuerdo con criterios más o menos variables, quiénes habrán de ser eliminados a fin de amedrentar a los demás miembros de la clase $\mathrm{e}$ inducirlos a modificar su comportamiento. Quienes no están incluidos en ella gozarían de la seguridad propia del Estado de derecho.

Esta tesis es sugestiva, pues parte del objetivo proclamado por quienes practican el terrorismo de Estado, es decir, la destrucción del enemigo subversivo con miras a reestablecer la paz interior. Sin embargo, su aceptación tropieza con no pocos inconvenientes. Significa, por una parte, rechazar la nota de la imprecisión de los hechos delictivos, cuya relevancia se ha intentado demostrar en b) y en d) y ha sido subrayada también por Raymond D. Duvall y Michael Stohl (1983, p. 185): "En el proceso de terror, nadie puede estar seguro pues, en realidad, la categoría de transgresión queda abolida. Cualquiera puede ser una víctima, sin que importe la acción que elija.” Por otra parte, implica también desconocer uno de los argumentos centrales de justificación de los actores del terrorismo de Estado, es decir, la imposibilidad de identificar a los enemigos con toda precisión. Ellos se presentarían "enmascarados", como decía Robespierre, o formarían parte de una confabulación, para usar la expresión de Trotsky. La tesis de la delimitación convierte al terrorismo de Estado en una variante - si se quiere más "benévola" — del totalitarismo; mientras en éste rige el principio: "Todos los enemigos deben ser eliminados", en aquél valdría la consigna: “Algunos enemigos deben ser eliminados". 
Pero la cuestión se complica justamente porque en el caso del terrorismo de Estado, la definición del "enemigo" es vaga. Con razón se pregunta Christoph Müller (1988, p. 230):

¿Qué tiene que hacer una persona para ser un "miembro de las fuerzas subversivas"! ¿Tiene que haber cometido actos terroristas? ¿O basta que, sin llegar a cometer delitos ella misma, "simpatice" con ciertos actos criminales de tales grupos terroristas? ¿Son parte de la subversión los familiares y amigos de terroristas? ¿Bastaba tal vez que en una agenda de un terrorista se encontrara escrito un nombre para incluir a esta persona también entre los subversivos y pertenecían entonces los nombres en la agenda de esta persona automáricamente a la subversión?

La respuesta la había dado ya tempranamente uno de los arquitectos del terrorismo de Estado en la Argentina, el general Ibérico Saint Jean:

Primero mataremos a los subversivos, luego a sus colaboradores, después a los simparizantes, más tarde a los indiferentes y, finalmente, a los tibios.

Desde esta perspectiva, la clase de los posibles destinatarios de las medidas de terrorismo de Estado poseen límites de aplicación tan inexactos y difusos que resulta difícil, cuando no imposible, determinar hasta dónde se extiende el "mundo social" (Christoph Müller) contra el que se dirigen sus medidas. Un buen ejemplo de la vaguedad de los límites de la clase de destinatarios de medidas terroristas del Estado es la clasificación de la población uruguaya establecida por el gobierno a partir de 1973 en grupos $A, B$ y $C$ (para mayores detalles al respecto, cfr. Peter Calvert, 1986, p. 40). También la Ley de sospechosos francesa del 17 de septiembre de 1793 -instrumento eficaz del terror estatal- definía a los "sospechosos" como "aquellos que, sea por su conducta, relaciones, sugerencias o escritos, han demostrado ser partidarios de la tiranía”. Con respecto al terrorismo de Estado en la Unión Soviética, A. James Gregor (1989, p. 161 s.) observa:

Hacia 1938, se lanzó un araque sistemático en contra de los “silenciosos", de aquellos que no habían participado en absoluto en los acontecimientos de los años anteriores. A menudo fueron arrestados y fusilados parientes, a veces remotos, de los "traidores". Nunca hubo ninguna sugerencia de que habían participado de alguna manera en actividades contrarrevolucionarias o antigubernamentales. La pregunta típica de las víctimas del terrorismo soviético era "ipor qué?"

Debido a la vaguedad de la clase de los destinatarios de las medidas coactivas, no pocos autores señalan la conveniencia de distinguir entre terrorismo de Estado y genocidio. La persecución nazi de judíos, gitanos u homosexuales o la masacre de comunistas en Indonesia en 1965-1966 se proponía la destrucción física de estas personas, pero esta estrategia criminal no apuntaba 
a despertar el temor en quienes sabían que no pertenecían a esos grupos ( $c f r$. al respecto Christopher Mitchell et al., 1986, p. 4; Ted Robert Gurr, 1986, p. 47). El genocidio es un asesinato en gran escala pero la intimidación no es una condición necesaria del mismo (cfr. Barbara Harff 1986, p. 164; Ted Robert Gurr 1986, p. 47). En cambio, el terrorismo de Estado puede, desde el punto de vista estadístico, provocar un número relativamente reducido de víctimas directas sin por ello dejar de serlo, siempre y cuando satisfaga la condición de intimidación.

El efecto de intimidación es, en este sentido, más basico que el de la destrucción real del "enemigo". Un régimen que logre intimidar en virtud de su arbitrariedad coactiva puede ser incluido en la categoría del terrorismo de Estado, aun cuando no logre destruir al "enemigo" (tal fue el caso, por ejemplo, de las medidas de terror impuestas por Fulgencio Batista a fines de los años 50 en Cuba y por Anastasio Somoza a fines de los 70 en Nicaragua). Y, desde luego, su destrucción puede lograrse sin necesidad de recurrir al terrorismo de Estado (como en el caso del genocidio político en 1965-1966 en Indonesia; cfr. Ted Robert Gurr 1986, p. 47). Si no se admite que tal es el caso, se corre el peligro de volver a confundir genocidio, totalitarismo y terrorismo de Estado.

La conjunción de estas características permite formular la siguiente definición de terrorismo de Estado:

El terrorismo de Estado es una forma del ejercicio del poder estatal cuya regla de reconocimiento permite y/o impone, con miras a crear el temor generalizado, la aplicación clandestina, impredecible y difusa, también a personas manifiestamente inocentes, de medidas coactivas prohibidas por el ordenamiento jurídico proclamado, obstaculiza o anula la actividad judicial y convierte al gobierno en agente activo de la lucha por el poder.

Esta definición del terrorismo de Estado puede ser complementada y explicitada haciendo referencia a sus elementos funcionales más importantes desde el punto de vista de su imposición. Para ello, resultan esclarecedoras algunas consideraciones de Ota Weinberger (1987, p. 4 ss.) que, aunque vinculadas con otras formas de persecución estatal (la de los disidentes religiosos), valen para el presente caso. El terrorismo de Estado requiere:

i) Una cierta organización ideológica cuya base es un dogma, una idea que vale como pauta absoluta, incuestionable, y que sirve de excusa o justificación para la destrucción de todo aquello que se oponga a ella. Tal fue el papel de la llamada "doctrina de la seguridad nacional" y de las tesis sustentadas por una buena parte de la jerarquía eclesiástica argentina:

La lucha antiguerrillera es una lucha por la República Argentina, por su integridad, pero también por sus altares [...] Esta lucha es una lucha en defensa de la 
moral, de la dignidad del hombre, en definitiva es una lucha en defensa de Dios [...] Por ello pido la protección divina en esta "guerra sucia" en que estamos empeñados. (Monseñor Victorio Bonamín; cfr. Emilio F. Mignone 1986, p. 24)

El informe presentado por Robespierre, en nombre del Comité de Salud Pública, el 5 de febrero de 1794, “Sobre los principios de moral política que deben guiar la Convención Nacional en la administracion interior de la República" es un buen ejemplo del dogma del "despotismo de la libertad" y del "santuario de la verdad". Dirk Coetzee afirma coherentemente: "Yo estaba cien por ciento convencido de que tales acciones eran correctas..." (cfr. entrevista citada).

ii) Un equipo eficaz de propaganda. La función esencial de este equipo es:

Emocionalización de la propia concepción y estigmatización moral del adversario. A través de la institución, se refuerza lo más posible el matiz emocional de la convicción y se dota a las opiniones opuestas de un estigma moral negativo. Quien piensa de otra manera es convertido en una persona negativa, portadora del Mal. (Weinberger, 1987, p. 21)

La llamada "Asociación Patriótica Argentina", con sus publicaciones tales como La Argentina y sus derechos humanos, y el Centro Piloto de París, para contrarrestar la "campaña antiargentina en el exterior" son ejemplos de la labor de estos equipos. Vinculado a esta actividad se encuentra:

iii) El cultivo de la propia imagen como medio para la compensación de actos de crueldad:

Se emplean medios tácticos a fin de mantener la imagen moral, a pesar de que amplios sectores de la población tienen conciencia de que, en realidad, se cometen acciones horrendas [...] Aquí hay que incluir el mantenimiento en secreto total o parcial de las medidas de violencia. (Ibid., p. 21 s.)

Es bien conocido el hecho de que las fuerzas represoras argentinas procuraron mantener siempre una suerte de "independencia sectorial", que dificultaba la imputación de las medidas de violencia ilegal a la vez que permitía a cada arma mantener su buena imagen ante el exterior. El Dr. Arslanian, defensor del brigadier general Omar D. Graffigna, basó su alegato en el juicio contra las juntas militares argentinas aduciendo justamente esta "independencia sectorial":

si pretendieran imputarle algún ilícito en la lucha contra la subversión no ocurrido dentro de su área, y simplemente por el hecho de haber sido integrante de la Junta Militar, estarían falseando la verdad porque la Junta Militar nunca tuvo la 
responsabilidad de la lucha contra la subversión, sino que ésta fue de cada fuerza en su jurisdicción. (Cfr. El Diario del Juicio, no. 29, 11 de diciembre de 1985)

iv) Disciplina interna de las organizaciones ideológicas: eliminación de la capacidad de autocrítica de los miembros de la organización encargada de aplicar las medidas coactivas a través de mecanismos tales como:

Disposiciones que hacen depender la carrera de la opinión ortodoxa; la necesidad por parte de los miembros de la comunidad de convicción de presentarse como buenos seguidores; una política unilateral de dotaciones económicas; censura... (Ibid., p. 21)

Los argumentos utilizados en favor de la obediencia debida y la comunidad de convicción reiteradamente expresada por los miembros de las fuerzas armadas argentinas documentan el grado de "disciplina interna" alcanzado durante el llamado "Proceso de reorganización nacional" por los organismos encargados de la represión. Hannah Arendt (1976, especialmente p. 294) ha analizado con todo detalle esta actitud de rechazo de toda autocrítica en el caso concreto de Adolf Eichmann.

Ota Weinberger se refiere a este tipo de elementos funcionales como recursos aptos para provocar desde el gobierno desarrollos inhumanos y destructivos en una sociedad. Esto no significa, en modo alguno, que quienes los practican no crean en la necesidad y justificabilidad de los mismos. Por ello conviene analizar el aspecto de su legitimación.

\section{La legitimación del terrorismo de Estado}

Si se acepta la distinción aquí propuesta entre legitimación y legitimidad y que la legitimación es condición necesaria para la existencia de todo sistema político, habrá que admitir también que el régimen de terrorismo de Estado posee legitimación y, por lo tanto, quienes adoptan frente a su regla de reconocimiento el punto de vista interno creen en su legitimidad. Para saber si esta presunta legitimidad es realmente tal, es decir, si es sostenible también desde el punto de vista de un observador que adopte el punto de vista ético, es conveniente analizar cuáles son los argumentos a los que recurren quienes propician y/o practican medidas de gobierno que permiten incluir su sistema político en la categoría de "terrorismo de Estado". Esta inclusión es realizada, desde luego, por el observador, pues es obvio que, dada la connotación moralmente negativa de la expresión "terrorismo de Estado", ningún sistema político se autocalifica como tal. En este sentido, los argumentos que aquí interesan son los utilizados para excusar o justificar la aplicación de aquellas medidas que justamente son definitorias del terrorismo de Estado. Entre los más frecuentemente aducidos se cuentan los siguientes: 
1) El argumento de la eficacia: la imposición del terror estatal es la forma más eficaz de combatir el terrorismo urbano y/o rural:

Dichos oficiales sostenían que en la medida que luchaban contra la "subversión" que adquiría formas de guerra irregular [...] los recursos que el Estado de derecho reglaba para castigar los delitos contra la Nación, la seguridad del Estado y la propiedad, resultaban totalmente ineficaces [...] Lo que hacía necesarias [...] formas "no convencionales" de respuesta. (Martín Gras, en Eduardo L. Duhalde, 1983, p. 77)

El argumento de la ineficacia de las instituciones judiciales fue, como es sabido, uno de los principales argumentos justificatorios del Esquadrón de la Muerte en el Brasil (cfr. H. Jon Rosenbaum y Peter Sederberg, 1976, p. 10).

2) El argumento de la imposibilidad de identificar al terrorista: ello exige la aplicación difusa de medidas coactivas:

No hay otra forma de identificar a este enemigo oculto —decían- si no es mediante la información obtenida por la tortura, y ésta, para ser eficaz, debe ser ilimitada, lo que nos coloca fuera de las reglas del juego del Estado tradicional. De esta manera, al asumir la lucha clandestina, se obtiene ventaja sobre el enemigo y además se persuade por el terror. (Gras, loc. cit., p. 77)

3) El argumento de la simetría de medios de lucha: la respuesta cabal al terrorismo indiscriminado es el reforzamiento del monopolio de la violencia estatal a través de medios equivalentes a los que utiliza el terrorista urbano y/o rural:

Aquélla fue una "guerra sucia". Los que la hicieron sucia fueron los subversivos. Ellos eligieron las formas de la lucha y determinaron nuestras acciones. (Ramón J.A. Camps, en Duhalde, 1983, p. 83)

El accionar de los dos bandos en lucha exige para que estas limitaciones [las de las leyes de la guerra y las del derecho internacional] sean obligatorias que ambos contendientes las respeten en virtud de lo cual, cuando uno de los adversarios las desconoce y viola, el otro riene el derecho de proceder de la misma manera. (Defensor del ex almirante Emilio Eduardo Massera, Dr. Prats Cardona; cfr. $E l$ Diario del Juicio, no. 24, 5 de noviembre de 1985)

No utilizar los mismos medios del adversario equivaldría a "luchar con las manos atadas a la espalda" "luchar según reglas que se sabe el adversario no respetará” (cfr. Grant Wardlaw, 1989, p. 380).

Esta es la tesis del tu quoque o la del "aullido del lobo", para usar una frase del defensor del almirante Armando Lambruschini, Dr. Goldaracena: 
"cuando se vive entre lobos, hay que aullar como ellos" (cfr. El Diario del Juicio, no. 30, 17 de diciembre de 1985). Conviene tener presente que quien aúlla aquí es el gobierno. Pero sobre esto se tratará más adelante.

4) El argumento de la distinción entre ética pública y ética privada: en el campo de la política, desde el punto de vista ético, a diferencia de lo que sucede en el ámbito de las acciones privadas, lo decisivo para juzgar el comportamiento de quienes detentan el poder es el resultado alcanzado. Si el resultado logrado por la vía del terrorismo de Estado es la paz, se obtiene así el fundamento necesario para una verdadera sociedad democrática:

Las críticas no consideran [...] los fines por los cuales lucharon las Fuerzas Armadas: el éxito que se obtuvo y sus consecuencias actuales, que permitieron la restauración de la democracia y de las instituciones republicanas. (Defensor del ex almirante Massera, cfr. El Diario del Juicio, no. 22, 22 de octubre de 1985)

La ética tomista y -diríamos-católica, distingue prolijamente entre la intención del agente (forma esencial del acto moral) y el objeto del acto (su materia moral); y la bondad o la maldad de un elemento del acto es independiente de la del otro [...] si nuestro problema es determinar si el acto es eficaz o no, si está ordenado o no al fin propio de la acción, entonces hacemos abstracción de la intención, para atender sólo al objetivo y las circunstancias. El juicio de los actos públicos, precisamente por ser públicos, se hace así. (Marcial Castro Castillo, 1979, p. 62)

5) El argumento de la inevitabilidad de consecuencias secundarias negativas: el fin que persigue la imposición de medidas difusas y clandestinas de represión es la paz y la seguridad. Que como efecto secundario ello implique la destrucción de vidas humanas, es algo perfectamente justificable si se recuerda la "teoría del doble efecto", sustentada por los escolásticos:

La distinción entre los efectos intencionados y los meramente previstos de una acción voluntaria es por cierto absolutamente esencial para la ética cristiana. Pues el Cristianismo prohíbe un gran número de cosas por ser malas en sí mismas. Pero, si he de ser responsable por las consecuencias previstas de una acción u omisión tanto como por la propia acción, estas prohibiciones se derrumban. Si alguien inocente ha de morir a menos que realice algo malo, desde esta perspectiva soy su asesino si me niego a realizarlo; por lo tanto, lo único que me quedaría sería sopesar los males. Aquí aparece el teólogo con el principio del doble efecto: 'No, no eres un asesino si la muerte de la persona no era tu fin ni tu medio elegido y si tenías que actuar en la forma que conducía a aquélla o en caso contrario hacer algo absolutamente prohibido." (G.E.M. Anscombe, 1971, p. 293 s.)

6) $\mathrm{El}$ argumento de las "elecciones trágicas": el terrorismo urbano y/o rural coloca al Estado frente a una situación que podría ser calificada como de 
"elección trágica": si no se da respuesta al terrorismo de una manera eficaz, se pone en peligro la existencia misma del Estado; por otra parte, una respuesta eficaz exige la aplicación de medidas al margen de la legalidad. En ambos casos están en juego valores primarios de la convivencia humana; lo fundamental es, desde luego, garantizar la existencia del Estado:

Las fuerzas legítimas del Estado suelen quedar aprisionadas entre la angustiosa demanda de seguridad de sectores golpeados por la subversión y fuerzas políticas contrarias al gobierno en ejercicio, siempre dispuestas a explotar en su favor fallas humanas o errores reales de la policía y el ejército. (Defensor del ex general Roberto Eduardo Viola, Dr. Marutian, El Diario del Juicio, no. 28, 3 de diciembre de 1985)

Ricardo Sidicaro (1990, p. 6), al referirse a la situación argentina, observa:

Los análisis ideológicos se caracterizan por plantear un diagnóstico interesado del problema que abordan, ya que el ideólogo sabe, o cree conocer, cuál es la solución. La estrategia expositiva reside en mostrar la gravedad de la situación, casi-sin-salida, para luego señalar la única alternativa, que-puede-ser-la-última, para encontrar la respuesta salvadora. De allí que sea usual en los discursos ideológicos alertar sobre la catástrofe que se avecina y proponer el modo de combatirla.

7) El argumento de la primacía de valores absolutos: existen valores político-sociales que valen absoluta $\mathrm{e}$ incondicionadamente. Su realización es condición necesaria (y, en algunos casos, hasta suficiente) para la felicidad y el bienestar de la sociedad. Quienes se oponen a ellos, sea dudando acerca de su incuestionabilidad, sea dificultando en la práctica su realización, se convierten en enemigos irreconciliables del orden social y, por lo tanto, su eliminación está justificada:

nuestra civilización no es contradictoria como la estupidez democrática liberal [...] Podemos aniquilar la subversión sin dejar de ser buenos cristianos; es más: la condición del triunfo es que sepamos ser mejores cristianos a través de la pelea, mediante la guerra victoriosa, cumpliendo nuestra misión de soldados de Cristo y de la Patria. (Marcial Castro Castillo, 1979, p. 32 s.)

Los que nieguen a esos fines y principios provenientes de nuestra espléndida tradición católica, directamente se enrolan en el enemigo; vale decir, se definen revolucionarios rebeldes al orden natural y al magisterio de la Iglesia. (Ibid., p. 31)

Los militares argentinos recurrieron a valores absolutos como los aquí expuestos. Otros regímenes de terrorismo de Estado aceptaron, desde luego, otros valores supremos. Basta recordar la ideología de la virtud de Robespierre o la Weltbild nacionalsocialista. 


\section{La ilegitimidad del terrorismo de Estado}

Veamos más de cerca estos siete argumentos:

1) El argumento de la eficacia está directamente vinculado con la estabilidad del régimen que recurre a la estrategia del terrorismo de Estado. Por ello, conviene distinguir entre el uso de la misma por parte de gobiernos totalitarios o democráticos. En el primer caso, dada su obvia ilegitimidad, las medidas de coacción terrorista tendientes a estabilizarlo no pueden ser nunca éticamente justificables, aun cuando el cálculo de costos-beneficios pueda parecer favorable.

En el caso de sistemas democráticos, el recurso al terrorismo de Estado contradice directamente la naturaleza de estos regímenes. Ello es lo que permite poner en duda el carácter democrático de algunos gobiernos centroamericanos y explica la preocupación jurídico-moral que despierta la legislación antiterrorista en los países democráticos. Basta pensar en las discusiones que provocara la Prevention of Terrorism Act de 1976 en Gran Bretaña (cfr. Grant Wardlaw, 1986), en la República Federal de Alemania la legislación antiterrorista a mediados de los años 70 ( $c f r$. al respecto, entre otros, Josef Augstein, 1976) y en Italia la legislación de emergencia y las disposiciones vinculadas con los llamados "terroristas arrepentidos" (arts. 4 y 5 del Decreto Ley 625/79 o 1-5 de la Ley 304/82) que, según algunos juristas, habría "contaminado por largo tiempo el sistema jurídico italiano” (cfr. Julio Padovani, 1987, p. 55). $\mathrm{El}$ argumento de la eficacia es falso y posiblemente lo es porque no toma en cuenta que una respuesta eficaz al terrorismo tiene que dar satisfacción simultánea a una doble exigencia: el afianzamiento de la legitimidad del sistema y la deslegitimación del desafio terrorista. Esta doble exigencia vale tanto con respecto a la posible superación de las causas del terrorismo cuanto con respecto a los medios utilizados para combatirlo. Por ello tiene razón Martha Crenshaw $(1983$, p. 33) cuando afirma:

El argumento según el cual la lucha contra el terrorismo requiere el uso de métodos terroristas no sólo es moralmente aborrecible sino políticamente desastroso [...] Tanto la historia de los resultados del terrorismo como el análisis de su relación con la legitimación de los regímenes apoyan la tesis que sostiene que la tolerancia de un antiterrorismo de derecha tiene efectos desestabilizadores.

2) El argumento de la imposibilidad de identificar al enemigo es una variante de lo que podría ser llamada la tesis herodiana de prevención de males futuros. La tesis es falsa ( $\mathrm{y}$ hace 2000 años fracasó estrepitosamente), a menos que con él tan sólo se quiera decir que no siempre es posible identificar al terrorista probable o potencial. Pero, esta afirmación vale en la misma medida en que vale la frase que sostiene que no siempre es posible identificar a la persona que probablemente cometerá un delito. Inferir de aquí la necesidad no 
sólo de detener sino de condenar a la muerte o la tortura a todo sospechoso es sustentar la tesis de la necesidad de la "represión preventiva" o de la "matanza por anticipado" (cfr. Carlos A. Brocato, 1985, p. 254). La concepción de la matanza por anticipado suele ser utilizada por quienes practican el genocidio étnico y parece haber sido la premisa justificatoria invocada por Talat Pascha, uno de los dirigentes turcos de la masacre de armenics, en la primavera de 1915, en la región de Van. Cuando el corresponsal del Berliner Tageblatt le preguntó por qué tenían que morir tantas personas inocentes junto con las culpables, respondió que los inocentes podían algún día convertirse en culpables (cfr. Lawrence S. Leshnik, 1990, p. 42). Pero, justamente el deber de distinguir entre el delincuente probable o potencial (aún no identificado) y el delincuente real (identificado y declarado tal por la vía judicial) es uno de los fundamentos del Estado de derecho.

3) El argumento de la equivalencia de medios suele ser una reformulación del argumento de la eficacia. En ese caso, vale lo dicho más arriba al respecto.

Pero hay algo más que debe ser tenido en cuenta. Johan Galtung ha señalado la asimetría que existe entre el terrorismo (privado) y el terrorismo de Estado (para una versión más matizada de esta tesis, cfr. Raymond D. Duvall y Michael Stohl, 1986, p. 208 ss.). Si bien es cierto que en ambos casos el terrorismo es, por definición, directamente violento,

el terrorismo es habitualmente el arma del débil contra el Estado fuerte; el terrorismo de Estado es el arma del Estado fuerte contra el débil [...] El terrorismo está vinculado con la asimetría del poder. (Galtung, 1988, p. 33)

Andrew Mack ha sostenido convincentemente que los "grupos terroristas son, por su propia naturaleza y por las estrategias que persiguen, incapaces de plantear ninguna amenaza seria a los Estados democráticos" (citado por Grant Wardlaw, 1986, p. 202). Por ello, el argumento de la equivalencia de medios es también falaz. Los resultados del terrorismo de Estado no son los que podrian esperarse en caso de existir medios de violencia aproximadamente equivalentes, sino la expresión de una clara desigualdad de poder: el terrorismo de Estado suele conducir a la masacre del adversario real o imaginario (cfr. al respecto los datos estadísticos presentados por John W. Sloan, 1983, p. 390). Viola, con ello, el principio de proporcionalidad, elemento indispensable de todo uso legítimo de la violencia (cfr. Ted Robert Gurr, 1986, p. 48 ss.).

4) La distinción entre moral pública y privada sobre la base de los resultados obtenidos suele invocar la conocida distinción de Max Weber entre "ética de la responsabilidad" y “ética de la convicción": 
No es posible colocar bajo un mismo techo la ética de la convicción y la ética de la responsabilidad o decretar éricamente cuál fin ha de justificar cuál medio, si se hace alguna concesión a este principio. (1971, p. 553)

A esta argumentación subyace la llamada razón de Estado y una concepción de la legitimidad que tiende a identificarla con la estabilidad y la legitimación de los sistemas políticos.

Es indiscutible que las acciones del político afectan a un número muchísimo mayor de personas que las de un individuo en el ámbito privado. Pero, tanto en el ámbito público como en el privado, los destinatarios de la acción son los individuos y el reconocimiento de su individualidad prohíbe tratarlos como medios para la obtención o conservación de bienes distribuibles. Esto no significa que en la decisión política algunos intereses no hayan de ser sacrificados en aras de otros. Lo que se exige es que no se sacrifique un bien moral de un individuo en aras de un bien equivalente de otros u otros individuos. Esto es justamente lo que vuelve injustificable la esclavitud, los regímenes totalitarios y, por supuesto, el terrorismo de Estado.

Si se acepta que la acción política debe, por razones morales, tomar en cuenta a los individuos como entidades separadas y no como partes sustituibles o intercambiables de un todo social, puede concluirse que el respeto a la personalidad individual es un imperativo que rige también para la acción política. Por ello es éticamente injustificable la aplicación difusa de medidas de terror, con total prescindencia de la identidad de los destinatarios de las mismas, bajo el pretexto de que de esa manera se eliminan las "fisuras legales" y no "se escurre" ningún culpable (para usar expresiones del ex almirante Emilio Massera, 1979, p. 62).

5) La doctrina del doble efecto se apoya en la distinción entre la acción intencionada y los resultados secundarios previstos, pero no intencionados, para juzgar acerca de la responsabilidad del actor. En Jerusalén, Adolf Eichmann adujo que su intención no había sido matar sino tan sólo obedecer órdenes. Las juntas militares argentinas sostuvieron que su intención no era matar o torturar sino redimir al país.

En América Latina, la apelación a la intención vinculada con la idea del doble efecto ha sido reiteradamente utilizada para reducir o excusar responsabilidades por parte de los gobiernos totalitarios. El 10 de mayo de 1974, el Times de Londres informaba acerca de una denuncia de genocidio de grupos indígenas en el Paraguay, presentada por la Conferencia Episcopal Paraguaya y la reacción del gobierno:

Al día siguiente, el Ministro de Defensa paraguayo, General Marcial Samaniego, convocó una conferencia de prensa para discutir estas acusaciones. El ministro no intentó negar que se habían cometido crímenes contra los indios. Subrayó, sin 
embargo, que no había habido intención de destruir a los Guayaki y que entonces, por definición, quedaba excluido el genocidio. "A pesar de que han habido víctimas y victimarios, no existe el tercer elemento necesario para establecer el crimen de genocidio, es decir, intención. Por lo tanto, si no ha habido intención, no se puede hablar de genocidio." [Subrayado en el original.]

Dados los problemas vinculados con el conocimiento cabal de la intención del actor, la doctrina del doble efecto tiene el enorme inconveniente de dejar exclusivamente en manos del agente la definición de la acción que realmente realiza y su posible justificación. Es una magnífica vía para conferir carácter moral a cualquier acción. En la práctica, como lo ha señalado G.E.M. Anscombe, permite calificar como "accidente" cualquier crimen. Tan sólo se trata de dirigir la atención "de una manera adecuada, es decir, pronunciar un pequeño discurso dirigido a uno mismo: Lo que yo intento hacer es. .. " (1971, p. 294).

En este sentido, la aplicación de la doctrina del doble efecto permitiría al gobierno que practica terrorismo de Estado negar que tal es el caso. Lo que se justifica aquí no es el terrorismo de Estado sino la acción cuya autoría se acepta; no se trata, por ejemplo, de justificar la tortura sino que se niega directamente que la acción intencionada sea torturar: lo que realmente se quería era obtener información y es ésta la acción realizada que requiere ser justificada.

La doctrina del doble efecto es éticamente inadmisible pues como permite justificar cualquier acción, equivale a una norma de comportamiento que deja en manos de sus destinatarios la exclusiva decisión acerca de cuándo ha sido violada, algo que contradice, por lo demás, el concepto mismo de norma.

6) El recurso al argumento de las elecciones trágicas supone la verdad del argumento 1) que, como se ha visto, es falso.

Además, cualquiera que sea la teoría que se acepte para la justificación moral del Estado, desde Locke hasta nuestros días, toda posición que tome en serio el interrogante anarquista, es decir, por qué no ha de ser mejor el noEstado que el Estado, parte de la aceptación de la autonomía del individuo, de la implantación de un sistema judicial que actúa pública e independientemente y de la publicidad de los actos del gobierno. No es necesario recordar aqui los argumentos kantianos en pro de la publicidad de la gestión gubernamental. Todas las justificaciones del Estado, aun las menos exigentes, incluyen por ello el elemento de la predicibilidad del castigo sobre la base de reglas de comportamiento conocidas. El terrorismo de Estado consiste precisamente en la negación de los requisitos mínimos cuya satisfacción permite iniciar la vía de la justificación del Estado. Por ello, la "Rule of terror" contradice directamente la "Rule of law". 
Dicho con otras palabras: en el momento en que el gobierno se transforma en agente del terror indiscriminado o difuso, vuelve a crear las condiciones propias del estado de naturaleza en el que la vida del hombre se vuelve "desagradable, brutal y corta”, para usar la conocida formulación de Hobbes. Es interesante por ello, recordar una vez más que una de las defensas aducidas en el juicio contra los integrantes de las juntas militares argentinas fuera la aceptación de la necesidad de que el gobierno se comportase como un lobo entre lobos. Es la "tesis del aullido", a la que me he referido más arriba: el gobierno abandona su papel de ejecutor de las leyes vigentes para transformarse en contendiente de la lucha por el poder. En este sentido, el terrorismo de Estado termina socavando las propias bases de justificación de la organización política y contribuye a su inestabilidad. El terrorismo de Estado no puede, por ello, ser nunca una forma permanente de gobierno. Así lo reconocen también quienes lo propician o practican cuando subrayan el carácter transitorio de este tipo de sistema como etapa preparatoria para una "democracia verdadera".

Desde el punto de vista ético, postular el “aullido gubernamental” como vía para el afianzamiento de la democracia es tan inaceptable como propiciar la muerte intencional de inocentes para amedrentar a los culpables reales o probables.

Quien, no obstante todo lo aquí expuesto, quisiera justificar las medidas propias del terrorismo de Estado podría aducir, como último argumento, la obligación moral de imponer, en caso necesario también con medios violentos, aquellas verdades políticas (por ejemplo, la defensa del mundo occidental y cristiano) que se admiten como absolutas y que son utilizadas como fundamento de los ideales de vida social que se propician:

porque el grito "viva la muerte" de Millán Astray, cuya ideología fuera calificada aquí de perversa, cobra sentido [... ] Al grito del fundador de los tercios legionarios, murieron muchos españoles para que la España sea la España democrática de hoy, y no gima bajo el yugo asfixiante al que está sometida media Europa. (Defensor del brigadier Orlando Agosti, Dr. Garona, cfr. El Diario del Juicio, no. 27, 26 de noviembre de 1985)

Si existen verdades políticas absolutas, ¿por qué un gobierno que las conoce ha de tolerar la vigencia de creencias opuestas y, por consiguiente, falsas? Quien se rebela contra el "orden natural", ino merece acaso ser combatido, también al grito de "viva la muerte"? ¿No es la aceptación de ideales politicoreligiosos una de las formas más dignas de practicar una vida moralmente coherente en una comunidad? Como lo demuestran las declaraciones de los ex comandantes de las juntas militares argentinas, un buen número de quienes practicaron o consintieron el terrorismo de Estado partieron de la base de que son justamente los ideales los que dan sentido a la vida y en su defensa hay 
que dejar de lado la tolerancia propia de la "estupidez democrática liberal” (Castro Castillo, loc. cit.).

Esta argumentación se basa en dos premisas: a) la afirmación de la existencia de verdades absolutas en la moral; b) la creencia en la necesidad moral de hacer valer los propios ideales, basados en estas verdades, aun cuando ello lesione los intereses de los demás. De aquí infiere la licitud moral de la intolerancia frente a quienes pongan en duda a) o se opongan a la puesta en práctica de b).

Con respecto a estas premisas, propias del absolutismo y del fanatismo morales, cabe señalar lo siguiente:

a) El absolutismo moral sostiene que en ningún caso está permitido violar los principios éticos y que ellos son racionalmente incuestionables. Su aceptación es un acto de fe inmune a toda duda. En tanto tal, no sólo no requiere sino que rechaza todo intento de fundamentación racional. Quienes comparten esta fe tienden a formar grupos cerrados en donde todos los que no pertenecen a ellos son calificados de seres moralmente deficitarios cuando no se les imputa ser la encarnación misma del mal:

Hay que limpiar al país de subversión, pero hay que entender que no sólo son subversivas las organizaciones terroristas de la ideología que fueren, sino que subversivos son también los saboteadores ideológicos, y aquellos que con soluciones fáciles inciten a una nueva postergación de nuestro destino. (Massera, 1979, p. 22)

El error del absolutismo moral reside principalmente en considerar que de la creencia en la verdad de una proposición o de un principio es posible derivar su verdad objetiva. Es obvio que quien cree en la verdad de $P$ considera que $P$ es verdadera. Desde el punto de vista interno, ello es correcto. Creencia y verdad coinciden:

Si existiera un verbo con el significado "creer falsamente", no tendría sentido la primera persona del presente del indicativo $[\ldots]$ "creo $[\ldots]$ y no es asi" sería una contradicción. (Ludwig Wittgenstein, 1960, p. 500)

Por eso, en el ámbito político, la legitimación puede ser definida como "creencia en la legitimidad". Pero, desde el punto de vista del observador externo, el hecho de que $X$ crea que $P$ es verdadero no es razón suficiente para aceptar la verdad de $P$ (a menos que se quiera recurrir al argumento de autoridad). Así como es contradictorio decir "creo que $P$, pero $P$ es falso", no tiene nada de sorprendente afirmar " $X$ cree que $P$ pero $P$ es falso".

Desde luego, la apelación a la propia creencia como criterio de verdad es circular: 
La razón es que, a menos que haya alguna forma de aplicar, desde un punto de vista impersonal, la distinción entre mi creer algo y su verdad, una apelación a su verdad es equivalente a una apelación a mi creencia en su verdad. (Thomas Nagel, 1987, p. 231)

Pero el absolutismo moral no sólo comete el error epistemológico de confundir creencia con verdad sino que, además, en la práctica social, sus consecuencias suelen ser trágicas, como lo demuestra la historia de las persecuciones a infieles (quienes no comparten la creencia moral o religiosa dominante) y los hechos que jalonan la vía del terrorismo de Estado.

b) En un libro ya clásico, R. M. Hare (1963, p. 159) definió tener un ideal como "creer que algún tipo de cosa es preeminentemente buena dentro de una clase más amplia". Cuando este ideal es perseguido para la conformación de la propia vida, hasta sacrificando los propios intereses, ello puede ser apropiado y, en ciertos casos, encomiable. El problema se presenta cuando la persecución de los ideales de un individuo o de un grupo se lleva a cabo sin tomar en cuenta para nada los intereses de los demás. Este es el caso del fanático político o religioso. Cuando los ideales del fanático son perversos, su grado de peligrosidad es enorme. Los ejemplos clásicos de este tipo de fanático son los casos del nazi o del fundamentalista islámico. Ambos son perfectamente coherentes con las posiciones que sustentan: cstán dispuestos a aceptar el castigo máximo en caso de que se demostrara que el primero tiene ascendencia judía o que el segundo ha violado algún principio religioso. El partidario del terrorismo de Estado podría ser incluido también en esta categoría de absolutistas morales.

Sin embargo, como hemos visto, existe una diferencia que distingue a los partidarios del terrorismo de Estado del nazi y del fundamentalista. Mientras en estos dos últimos casos, la clase de los "buenos" y de los “malos" esta delimitada en virtud de criterios claros de inclusión o exclusión y, por lo tanto, es relativamente fácil determinar quiénes pertenecen a ellas, en el caso del terrorismo de Estado, justamente porque sus medidas son difusas e impredecibles, no queda excluida la posibilidad de que quienes defienden o propician el terrorismo de Estado terminen siendo sus propias víctimas. En la reciente historia argentina, tan pródiga en todo tipo de atrocidades, se han dado también estos casos. El fanático del terrorismo de Estado, si quiere ser coherente, no puede, a posteriori, sentirse sorprendido por la propia tragedia sino que tiene que estar dispuesto de antemano a aceptar que él y su familia pueden ser sacrificados arbitrariamente y deberá sostener, además, que esta arbitrariedad le parece justa. Curiosamente, la coherencia del fanático conduce así a actitudes rayanas en la demencia: quien practica el terrorismo (sea estatal o no) sostiene, por definición, que está moralmente justificado - en aras de ideales superiores a los que se adhiere en un acto de fe-destruir vidas inocentes; personalmente se autocalifica de inocente e incluye en esta clase a las personas 
que más aprecia y a las que desea defender del enemigo, pero, en virtud de su actitud terrorista, tiene que conceder que una forma eficaz y justificable de defensa es admitir la posibilidad de su propia destrucción y la de sus seres más próximos, justamente por ser "inocentes".

Dada la falsedad de las dos premisas, es obvio que la conclusión de la licitud moral de la intolerancia es también falsa. Pero justamente en este punto, podría argumentarse al contrario y sostener que de aquí ha de inferirse la necesidad de tolerar el absolutismo ético y al fanático si no se quiere caer en un fanatismo inverso. La única respuesta al absolutismo moral sería el relativismo que, coherentemente interpretado, no permitiría la condena del fanático. Dicho de otra manera: si los argumentos en contra del absolutismo ético y del fanático son hechos en nombre de una posición democrática liberal, cuyo enfoque moral no debería ser absolutista sino relativista, no se entiende cómo es posible condenarlos. El hecho de que, sin embargo, se los condene, pondría de manifiesto cuán contradictoria es la "estupidez democrática liberal” (para recordar una vez más la expresiva frase del capellán militar Castro Castillo). Esta objeción exige alguna consideración de la oposición absolutismo-relativismo y una cierta precisión del concepto de tolerancia.

Por lo pronto, cabe señalar que la disyunción absolutismo o relativismo en modo alguno es exhaustiva cuando se trata de describir las posiciones posibles en el campo de la ética normativa. Cabe pensar en la vía del objetivismo ético, que admite la posibilidad de la fundamentación racional de los valores en la medida en que su aceptación equivalga a la promoción y protección de ciertos bienes considerados como indispensables para la vida y la salud del hombre, entendida esta última expresión en un sentido amplio, es decir, no sólo la vida física sino también política y social. Estos bienes son los que constituyen el núcleo de los llamados derechos humanos en las constituciones democráticas modernas. Su vigencia es condición necesaria para poder predicar la legitimidad de un sistema político. Dicho con otras palabras, su violación no puede ser tolerada desde el punto de vista moral. No cabe aquí ninguna argumentación relativista.

La vinculación entre la vigencia de los derechos humanos y la legitimidad no es una cuestión de mera creencia, como podría sostener un absolutismo benevolente, sino más bien la consecuencia necesaria de la adopción de un punto de vista moral, es decir, de una perspectiva que acepte criterios de imparcialidad y universalidad para el juicio acerca del comportamiento de seres racionales y autónomos reunidos en sociedad no para formar un club de suicidas sino para promover sus condiciones de vida. Esto significa, desde luego, que no toda convicción, por más fuerte que sea la creencia que la sustente, puede ser legítimamente impuesta a los demás, sin tomar en cuenta para nada los intereses de las personas afectadas, como sostiene el fanático. La tolerancia 
que garantiza la legitimidad no es la luz verde de la permisión total, que conduce al anarquismo moral. En el plano político, la distinción entre la anarquía y el Estado de derecho pasa justamente por la aceptación de un ámbito vedado a la intervención de quien detenta el poder.

Precisamente porque el fanático no está dispuesto a detenerse ante este coto vedado sino que irrumpe en él con pretensiones mesiánicas, es que no puede reclamar para sí los beneficios de la tolerancia. La tolerancia comienza a partir del coto vedado y tampoco admite como justificación de la imposición de pautas de conducta sociales la invocación de meras creencias personales. El problema de la legitimidad está estrechamente vinculado con la distinción "entre los valores a los cuales una persona puede apelar para conducir su propia vida y aquellos a los que puede apelar para justificar el ejercicio del poder político" (Thomas Nagel, 1987, p. 221). Por ello resultan también insuficientes para fundamentar la legitimidad de un sistema político los argumentos del “idealista moderado" (Alan Gettner, 1977, p. 163) si éste no está dispuesto a contener sus ideales ante el coto vedado y dar a sus argumentos una base accesible también a la comprensión racional de quienes no comparten sus ideales personales.

Las medidas propias del terrorismo de Estado suponen una regla de reconocimiento que contradice el núcleo mismo de toda posible justificación del Estado. Reestablecen las condiciones de la situación pre-estatal con una intensidad aún mayor: mientras los hombres-lobos de Hobbes tenían una igualdad de fuerzas aproximada, el "gobierno aullante" posee un poder tal que lo coloca al margen de todo interés en crear formas mínimamente aceptables de convivencia.

Quien frente a esta regla de reconocimiento adopta un punto de vista interno, es decir, cree en su legitimidad, al transformar sus propias creencias en criterio de verdad absoluta, se lanza por la vía del fanatismo y cierra toda posibilidad de recurrir a la argumentación política racional. En este sentido, el terrorismo de Estado puede cabalmente ser calificado como una forma demencial de gobierno.

\section{Bibliografía}

Anscombe, G.E.M., 1971, “War and Murder”, en James Rachels (comp.), Moral Problems, Nueva York.

Arendr, Hannah, 1976, Eichmann in Jerusalem, Munich.

Augstein, Josef, 1976, "Anwälte und Terroristen. Zur Behinderung der Verteidigung durch 'Anti-Terrorgesetze'”, en Rudolf Wassermann (comp.), Terrorismus contra Rechtsstaat, Darmstadt/Neuwied. 
Bourricaud, François, 1961, Esquisse d'une thérie de l'autorité, París.

Brocato, A. Carlos, 1985, La Argentina que quisieron, Buenos Aires.

Buchheim, Hans, 1985. Poltitica y poder, Alfa, Barcelona/Caracas.

Calvert, Peter, 1986, "Terror in the Theory of Revolution", en Noel O'Sullivan (comp.), Terrorism, Ideology, and Revolution, Sussex.

Carter, Michael Phillip, 1989, "The French Revolution: 'Jacobin Terror'”, en David C. Rapoport y Yonah Alexander (comps.), The Morality of Terrorism. Religious and Secular Justifications, Nueva York.

Castro Castillo, Marcial, 1979, Fuerzas Armadas. Ética y represión, Buenos Aires.

Crenshaw, Martha, 1983, Terrorism, Legitimacy, and Power. The Consequences of Political Violence, Middletown, Conn.

Dallin, Alexander, George Breslauer, 1970, Political Terror in Communist Systems, Stanford University Press, Stanford.

Duhalde, Eduardo Luis, 1983, El estado terrorista argentino, Barcelona.

Duvall, Raymond D. y Michael Stohl, 1983, "Governance by Terror", en Michael Stohl (comp.).

Fishkin, James S., 1984, Beyond Subjective Morality, New Haven/Londres.

Galtung, Johan, 1988, "On the Causes of Terrorism and their Removal", Ifda dossier, no. 66 , julio/agosto.

Garzón Valdés, Ernesto, 1987, El concepto de estabilidad de los sistemas politicos, Madrid. Gettner, Alan, 1977, "Hare and Fanaticism", Ethics, vol. 87, no. 2.

Gregor, A. James, 1989, "Fascism's Philosophy of Violence and the Concept of Terror", en David C. Rapoport y Yonah Alexander (comps.), The Morality of Terrorism. Religious and Secular Justification, Nueva York.

Grosser, Alfred, 1989, Vermunft und Gewalt, Hanser, Munich.

Gurr, Ted Robert, 1986, "The Political Origins of State Violence and Terror:

A Theoretical Analysis", en Michael Stohl y George A. Lopez (comps.), Government Violence and Repression. An Agenda for Research, Nueva York/Westport, Conn./Londres.

Hare, R. M., 1963, Freedom and Reason, Oxford.

Harff, Barbara, 1986, "Genocide as State Terrorism", en Michael Stohl y George A. Lopez (comps.), Government Violence and Repression. An Agenda for Research, Nueva York/Westport, Conn./Londres.

Hart, H.L.A., 1961, The Concept of Law, Oxford.

Hedenius, Ingemar, 1981, “On Relativism in Ethics”, en Theoria, vol. XLVII, no. 3. Heller, Hermann, 1971, Gesammelte Scbriften, Leiden y Tubinga, 3 tomos.

Klug, Ulrich, 1987, "Die Rechtsprechung des Bundesgerichtshofes in NSProzessen", en Julius H. Schoeps y Horst Hillermann (comps.), Justiz und Nationalsozialismus, Burg-Verlag, Stuttgart/Bonn. (Ulrich Klug 1989: Problemas de la filosofia del derecho y de la pragmática del derecho, Barcelona.)

Krumm, Karl-Heinz, 1977, "Probleme der Organisation und Koordination bei der Terrorismus-Bekämpfung in der Bundesrepublik", en Manfred Funke (comp.), Terrorismus. Untersuchungen zur Struktur und Strategie revolutionärer Gewaltpolitik, Dusseldorf.

Leshnik, Lawrence S., 1990, "Vor den Augen des Waffenbruders", Dic Zeit, no. 17, 20 de abril de 1990, pp. 41-42. 
Lipset, Seymour M., 1959, “Some Social Requisites of Democracy: Economic Development and Political Legitimacy", American Political Science Review, no. 53.

Luhmann, Niklas, 1969, Legitimation durch Verfalsen, Neuwied.

Massera, Emilio E., 1979, El camino de la democracia, Buenos Aires.

Mignone, Emilio E., 1986, Iglesia y dictadura, Buenos Aires.

Mitchell, Christopher, Michael Stohl, George A. Lopez, 1986, "State Terrorism: Issues of Concept and Measurement", en Michael Stohl y George A. Lopez (comps.), Government Violence and Repression. An Agenda for Research, Nueva York/Westport, Conn./Londres.

Müller, Christoph, 1988, “El proceso militar a las juntas militares argentinas: Estado de derecho y derechos humanos", en Ernesto Garzón Valdés et al. (comps.), La nueva democracia argentina (1983-1986), Buenos Aires.

Murena, Héctor A., 1970, Polispucrcón, Buenos Aires.

Nagel, Thomas, 1987, "Moral Conflict and Political Legitimacy", Philosophy of Public Affairs, vol. 16, no. 3

Nicholson, Michael, 1986, "Conceptual Problems of Studying State Terrorism”, en Michael Stohl y George A. López (comps.), Government Violence and Repression. An Agenda for Research, Nueva York/Westport, Conn./Londres.

Padovani, Tulio, 1987, "Los instrumentos jurídicos y la lucha contra el terrorismo en la experiencia italiana", Revista juridica de Buenos Aires, vol. I.

Robespierre, Maximilian de, 1965, Discours, París.

Rosenbaum, H. Jon y Peter Sederberg, 1976, Vigilante Politics, University of Pennsylvania Press, Filadelfia.

Sidicaro, Ricardo, 1990, "Ideas de cuando las ideas se mataban", El Bimestre político y económico, no. 48, Buenos Aires.

Sloan, John W., 1983, "Political Terrorism in Latin America", en Michael Stohl (comp.).

Stohl, Michael (comp.), 1983, The Politics of Terrorism, Marcel Dekker, Inc., Nueva York/Basilea,

Trotsky, León, 1961, Terror and Communism, Ann Arbor, University of Michigan Press.

Wardlaw, Grant, 1982, Political Terrorism. Theory, Tactics, and Counter-measures, Cambridge.

- 1989, "Justifications and Means: The Moral Dimension of State-Sponsored Terrorism", en David Rapoport y Yonah Alexander (comps.), The Morality of Terrorism. Religious and Secular Justifications, Nueva York.

Wassermann, Rudolf, 1976, “Sicherung oder Aushöhlung des Rechtsstaats”, en Rudolf Wassermann (comp.), Terrorismus contra Rechtsstaat, Darmstadt/Neuwied.

Weber, Max, 1971, "Politik als Beruf", en Max Weber, Gesammelte Politische Schriften, Tubinga.

Weinberger, Ota, 1987, “Angst vor dem menschlichen Wahn”, en Anton GrabnerHaider, Ota Weinberger y Kurt Weinke (comps.), Fanatismus und Massenwahn, Graz/Viena.

Wise, David, 1978, The American Police State, Random House, Nueva York.

Wittgenstein, Ludwig, 1960, "Philosophische Untersuchungen", en Scbriften, Francfort del Meno. 